\title{
Electrostatic and solvation-thermodynamic approaches as a tool to study formation of electrical double layer of ionogenic surfactants micelles
}

\author{
Nikolay V. Bondarev \\ Department of Chemistry, V.N. Karazin Kharkiv National University, \\ 4 Svobody Sq., Kharkiv, 61022, Ukraine \\ E-mail:n_bondarev@ukr.net
}

Keywords: ionogenic surfactants micelles, electrical double layer, electrochemical potential, Stern layer, Galvany potential, primary medium effect.

The solvation-thermodynamic approach to study formation of electrical double layer of ionogenic surfactants micelles is proposed. The equations to estimate the Galvany potential of micelles formed by ionogenic surfactants are proposed. The apparent dissociation constant thermodynamic interpretation of the electrolyte in micellar solutions is given.

\section{Introduction}

The electrical double layer has a significant effect on the rate of electrochemical processes, the critical micellization concentration, adsorption of ions and neutral molecules, the disperse systems stability, wetting and other phase boundary properties. Quantitative measure of this influence is the electrostatic potential of charged micelles, the evaluation methods which are the subject of theoretical research [1] and experimental studies [2]. The goal of the current research was to develop the ideas about the mechanisms for formation of the electrical double layer of micelles formed by ionogenic surfactants on the basis of the solvation-thermodynamic approaches'. The
Figure 1 shows schematically the structure of the electrical double layer of micelles formed by long chain cation surfactants in aqueous solutions.

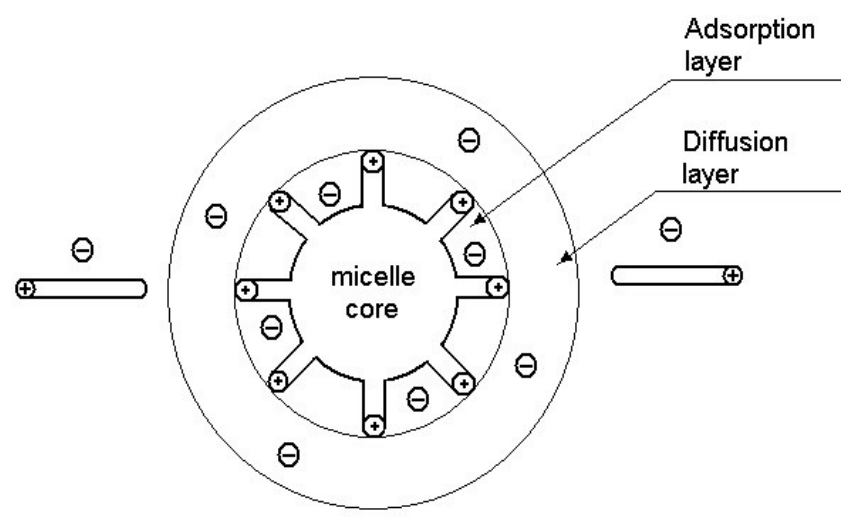

Figure 1. The structure of the electrical double layer of micelles of cationic surfactants in aqueous solutions.

The Stern region of micelles of ionic surfactants (an adsorption layer), in which the counter ions are localized, is sufficiently 
hydrated, and the originality of the micelles as the reaction medium is caused by the proximity of the hydrocarbon radicals (involving first and second methylene groups in the Stern region - "roughness" micelles) and water. This explains the similarity of micelles formed by ionic surfactants and mixtures of water with organic solvents of different nature [3]. Counter ions fall into gaps between the positively charged groups of ionogenic surfactants and partially neutralize the surface charge of the micelle.

The acid-base equilibrium play an important role in micellar solution processes [4].

\section{Electrostatic approach}

For the first time, the quantitative evaluation of the influence of the electrostatic potential (charge) of the micelles on the indicators strength and the surface acidity has been given in the Hartley's work [5] to explain the "protein" and "colloidal" error indicators. According to Hartley [6], the electrostatic Gibbs free energy of proton transfer from the bulk solution to the surface of charged micelles of cationic surfactant is $\Delta G^{e l}=-F \psi$, where $\psi$ is the electrostatic surface potential of micelles. If the protons in solution obey the Boltzmann distribution, then their concentration $c_{\mathrm{H}^{+}}^{m}$ at the surface of micelles, compared with the concentration in a volume (bulk) solution $c^{b}{ }^{+}$, is determined by the equation

$$
c_{\mathrm{H}^{+}}^{m}=c_{\mathrm{H}^{+}}^{b} \exp \left(-\frac{F \Psi}{R T}\right)
$$

Thus, the dissociation of weak acids (indicators) is suppressed in anionic micellar media and is facilitated in cationic micellar media. This means that in the case of a purely electrostatic approach to identifying the influence of the charge of the micellar phase on the strength indicator (weak acid), using the volume concentration of hydrogen ions, the observed (obsd) dissociation constant $\left(\mathrm{p} K_{a}\right)^{m, o b s d}$ differs by a amount of $\frac{F \psi}{2,303 R T}$ from $\mathrm{p} K_{a}^{b}$ in the volume aqueous solution, so that

$$
\psi=\frac{2.303 R T\left[\left(\mathrm{p} K_{a}\right)^{m, o b s d}-\mathrm{p} K_{a}^{b}\right]}{F}
$$

Stern proposed the first three-plane model of the electrical double layer (EDL), which was able to distinguish weakly and strongly adsorbed ions [7]. Taking into account the specific adsorption of molecular (HA) and anion ( $\left.\mathrm{A}^{-}\right)$forms of a weak electrolyte (Figure 2) on the pseudo phase surface [4], the dissociation equilibria of HA in adsorption layer (inner dense Stern layer $(m)$ ) and diffuse Gouy layer takes the form: $\mathrm{HA}^{(m)}=\mathrm{A}^{-(m)}+\mathrm{HS}_{\mathrm{S}}{ }^{+}$. 


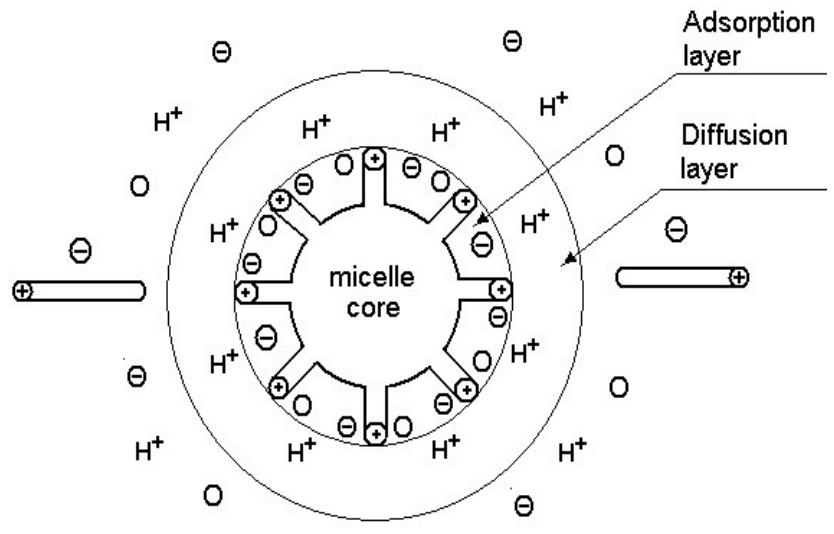

Figure 2. The structure of the electrical double layer micelles of cationic surfactants in aqueous solutions of carboxylic acids $\left(\mathrm{HA}=\mathrm{H}^{+}+\mathrm{A}^{-}\right)$in the case of specific adsorption of acid molecules and anions.

According to Stern, adsorption on the surface is possible only in a certain number of places available for the undissociated molecules $\mathrm{HA}$ and ions $\mathrm{A}^{-}$. In this case, hydrogen ions in the diffuse Gouy layer in the field of the potential of a charged micelle distribution are determined by the thermal motion in accordance with the Boltzmann law.

Acid-base equilibria is characterized by intrinsic dissociation constant

$$
K^{\text {int }}=\frac{\left[\mathrm{A}^{-}\right]^{m}\left[\mathrm{H}^{+}\right]_{S}}{[\mathrm{HA}]^{m}}
$$

and the concentration of hydrogen ions in the diffuse Gouy layer at a distance $x$ from the phase boundary is proportional to the Boltzmann factor

$$
\left[\mathrm{H}^{+}\right]_{S, x}=\left[\mathrm{H}^{+}\right]_{0}^{w} \exp \left(-\frac{F \psi_{x}}{R T}\right)
$$

where $\psi_{x}$ is the value of potential EDL in the diffuse layer, $-\lg \left[\mathrm{H}^{+}\right]_{S}$ - "surface acidity" (surface excess) at the boundary of a dense Stern layer and diffuse Gouy layer. Under the conditions of complete binding ( $c$ - complete) active centers of the micelle surface (Stern's presentation is largely based on physical adsorption theory of Langmuir [7]), both forms of the weak electrolyte, HA and $\mathrm{A}^{-}\left(x=\delta, \psi_{x}=\psi_{\delta}\right)$ (Stern's views is largely based on Langmuir physical adsorption theory), equation for the intrinsic dissociation constants becomes

$$
\begin{aligned}
& K^{i n t}=\frac{\left[\mathrm{A}^{-}\right]_{c}^{m}\left[\mathrm{H}^{+}\right]_{S, c}}{[\mathrm{HA}]_{c}^{m}}=\frac{\left[\mathrm{A}^{-}\right]_{c}^{m}}{[\mathrm{HA}]_{c}^{m}}\left[\mathrm{H}^{+}\right]_{0}^{w} \exp \left(-\frac{F \psi_{\delta}}{R T}\right)= \\
& =K^{a c} \exp \left(-\frac{F \psi_{\delta}}{R T}\right)
\end{aligned}
$$

here $K^{a c}=\frac{\left[\mathrm{A}^{-}\right]_{c}^{m}}{[\mathrm{HA}]_{c}^{m}}\left[\mathrm{H}^{+}\right]_{0}^{w}$ is the apparent dissociation constant; $\psi_{\delta}$ is the value of the Stern potential; $\left[\mathrm{H}^{+}\right]_{0}^{w}$ is the concentration of ions in the volume of aqueous solution.

Then

$$
\psi_{\delta}=\frac{2.303 R T\left(\mathrm{p} K^{i n t}-\mathrm{p} K^{a c}\right)}{F}
$$

Large scattering in the values of $\psi \delta$, evaluated by different authors [8] using indicators for ionic surfactant micelles, indicates a significant influence of medium effects on the electrical properties boundary between the pseudo phase of ionic surfactant 
and the aqueous solution, and therefore on the limitations of the electrostatic approach and Stern's views on the interpretation of acidbase equilibria in micellar solutions.

\section{Solvation-thermodynamic approach}

In the development of ideas about the structure of EDL [9], an solvationthermodynamic approach was proposed for the electrical double layer formation in micellar solutions of ionic surfactants in the distribution of weak organic electrolytes (HA) between the aqueous and micellar phases (Figure 3).

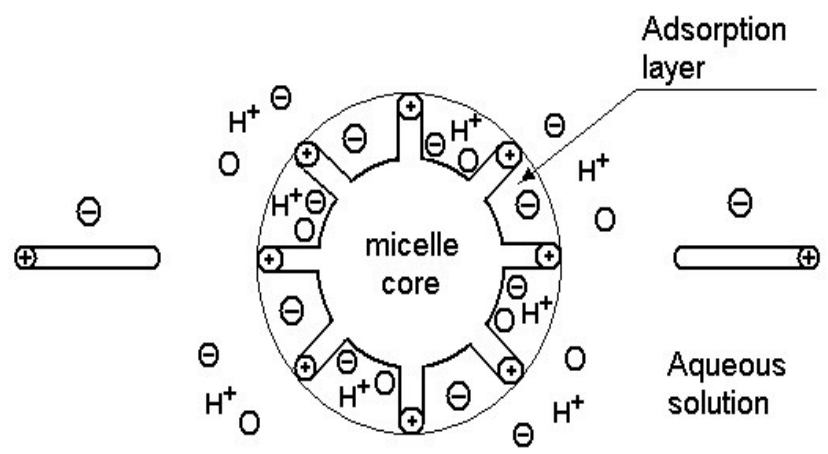

Figure 3. The structure of the electrical double layer of micelles of cationic surfactants in aqueous solutions by distribution of acid between the aqueous and the micellar phase.

The relationship between the thermodynamic dissociation constants of weak electrolyte in aqueous $\mathrm{KA}\left(K_{a}^{w}\right)$ and micellar $\left(K_{a}^{m}\right)$ solutions:

$$
\begin{aligned}
& R T \ln K_{\mathrm{a}}^{\mathrm{m}}= \\
& =R T \ln K_{\mathrm{a}}^{\mathrm{w}}+\Delta G_{\text {chem } \mathrm{KA}}-\Delta G_{\text {chem } \mathrm{K}^{+}}-\Delta G_{\text {chem }, \mathrm{A}^{-}}
\end{aligned}
$$

follows from a consideration of the thermodynamic cycle [10], written for the dissociation equilibria in aqueous and micellar phases:

$$
\begin{aligned}
& \mathrm{HA} \stackrel{-R T \ln K_{a}^{w}}{\longleftarrow} \mathrm{H}^{+}+\mathrm{A}^{-}(w) \\
& \downarrow \Delta G_{\text {chem }, \mathrm{HA}} \quad \downarrow \Delta G_{\text {chem }, \mathrm{H}^{+}} \downarrow \Delta G_{\text {chem, } \mathrm{A}^{-}} \\
& \mathrm{HA} \underset{-R T \ln K_{a}^{m}}{\rightleftarrows} \mathrm{H}^{+}+\mathrm{A}^{-} \quad(m)
\end{aligned}
$$

The equation describing the influence of the primary medium effects $\left(\gamma_{0}\right)$, equilibrium concentrations of particles ([HA], $\left[\mathrm{A}^{-}\right]$) and ionic strength (primary salt effect, $\left.\gamma^{*}\right)$ on the Galvani potential $\left(\Delta_{\mathrm{w}}^{\mathrm{m}} \varphi\right)$ of the phase boundary between the aqueous solution and micellar phase of cationic surfactants is given by

$$
\begin{aligned}
& -\Delta_{\mathrm{w}}^{\mathrm{m}} \varphi=\frac{2,303 R T}{z F} \times \\
& \times\left(\lg \gamma_{\mathrm{o}, \mathrm{H}^{+}}+\lg \frac{[\mathrm{HA}]^{\mathrm{m}} \gamma_{\mathrm{HA}}^{*, \mathrm{~m}}}{[\mathrm{HA}]^{\mathrm{w}} \gamma_{\mathrm{HA}}^{*, \mathrm{w}}}-\lg \frac{\left[\mathrm{A}^{-}\right]^{\mathrm{m}} \gamma_{\mathrm{A}^{-}}^{*, \mathrm{~m}}}{\left[\mathrm{~A}^{-}\right]^{\mathrm{w}} \gamma_{\mathrm{A}^{-}}^{*, \mathrm{w}}}\right)
\end{aligned}
$$

For the anions

$$
\frac{\left[\mathrm{A}^{-}\right]^{m} \gamma_{\mathrm{A}^{-}}^{*, m}}{\left[\mathrm{~A}^{-}\right]^{w} \gamma_{\mathrm{A}^{-}}^{*, w}}=\gamma_{\mathrm{o}, \mathrm{A}^{-}}^{-1} \exp \left(-\frac{{ }_{i} F \Delta_{w}^{m} \varphi_{\mathrm{A}^{-}}}{R T}\right),
$$

for the molecules

$$
\frac{[\mathrm{HA}]^{m} \gamma_{\mathrm{HA}}^{*, m}}{[\mathrm{HA}]^{w} \gamma_{\mathrm{HA}}^{*, w}}=\gamma_{\mathrm{o}, \mathrm{HA}}^{-1}
$$

Thus equation (8) is transformed into Izmailov's equation [10] 


$$
\mathrm{p} K_{a}^{m}-\mathrm{p} K_{a}^{w}=\lg \gamma_{\mathrm{o}, \mathrm{H}^{+}}+\lg \gamma_{\mathrm{o}, \mathrm{A}^{-}}-\lg \gamma_{\mathrm{o}, \mathrm{HA}}
$$

Here

$$
\mathrm{p} K_{a}^{m}-\mathrm{p} K_{a}^{w}=\frac{\Delta G^{\mathrm{o}}{ }^{+}, \mathrm{H}^{+} G^{\mathrm{o}} e l, A^{-}}{2.303 R T}
$$

in the standard conditions.

If the weak electrolyte (HA) is distributed between the aqueous solution and micelles formed by longchain anions and the adsorption-neutralization mechanism for formation of EDL is realized by neutralisation of the negative charge of the micellar surface cations, the anions of weak electrolyte become potential-determining. In this case

$$
\begin{aligned}
& \Delta_{\mathrm{w}}^{\mathrm{m}} \varphi=\frac{2,303 R T}{F} \times \\
& \times\left(\lg \gamma_{\mathrm{o}, \mathrm{A}^{-}}+\lg \frac{[\mathrm{HA}]^{\mathrm{m}} \gamma_{\mathrm{KA}}^{*, \mathrm{~m}}}{[\mathrm{HA}]^{\mathrm{w}} \gamma_{\mathrm{KA}}^{*, \mathrm{w}}}-\lg \frac{\left[\mathrm{H}^{+}\right]^{\mathrm{m}} \gamma_{\mathrm{H}^{+}}^{*, \mathrm{~m}}}{\left[\mathrm{H}^{+}\right]^{\mathrm{w}} \gamma_{\mathrm{H}^{+}}^{*, \mathrm{w}}}\right)
\end{aligned}
$$

For the standard state, the relationship between the thermodynamic dissociation constants of a weak electrolyte in aqueous and micellar phases has the form

$$
\frac{K_{a}^{m}}{K_{a}^{w}}=\frac{a_{\mathrm{H}^{+}}^{\mathrm{m}} a_{\mathrm{A}^{-}}^{\mathrm{m}} a_{\mathrm{HA}}^{\mathrm{w}}}{a_{\mathrm{H}^{+}}^{\mathrm{w}} a_{\mathrm{A}^{-}}^{\mathrm{w}} a_{\mathrm{HA}}^{\mathrm{m}}}=\gamma_{\mathrm{o}, \mathrm{H}^{+}}^{-1} \gamma_{\mathrm{o}, \mathrm{A}^{-}}^{-1} \gamma_{\mathrm{o}, \mathrm{HA}}
$$

The relationship (11) reveals the physical meaning (the thermodynamic nature) of "apparent" and "intrinsic" dissociation constants $[4,8]$ of weak electrolytes used in scientific practice:

$$
K_{a}^{a}=\frac{a_{\mathrm{A}^{-}}^{\mathrm{m}} a_{\mathrm{H}^{+}}^{\mathrm{w}}}{a_{\mathrm{HA}}^{\mathrm{m}}}=\frac{a_{\mathrm{A}^{-}}^{\mathrm{m}} a_{\mathrm{H}^{+}}^{\mathrm{m}} \gamma_{\mathrm{o}, \mathrm{H}^{+}}}{a_{\mathrm{HA}}^{\mathrm{m}}}=K_{a}^{m} \gamma_{\mathrm{o}, \mathrm{H}^{+}}
$$

$$
K_{a}^{i}=\frac{a_{\mathrm{A}^{-}}^{\mathrm{w}} a_{\mathrm{H}^{+}}^{\mathrm{w}}}{a_{\mathrm{HA}}^{\mathrm{w}}} \frac{\gamma_{\mathrm{o}, \mathrm{HA}}}{\gamma_{\mathrm{o}, \mathrm{A}^{-}}}=K_{a}^{w} \frac{\gamma_{\mathrm{o}, \mathrm{HA}}}{\gamma_{\mathrm{o}, \mathrm{A}}^{-}}
$$

Thus, the constants $K_{a}^{m}$ and $K_{a}^{a}$ characterize the electrolyte dissociation equilibria in the micellar pseudophase. However, whereas in the first case $\left(K_{a}^{m}\right)$ as the standard state $[10,11]$ for ions and molecules is a micellar solution, in the second case $\left(K_{a}^{a}\right)$ the standard state for the proton is an aqueous solution.

\section{Conclusions}

The

solvation-thermodynamic approach proposed for the study formation of electrical double layer of ionogenic surfactants micelles in aqueous weak acid solutions allowed to formulate the directions of experimental studies of electrochemical properties of real microheterogeneous system:

- The study of dissociation equilibrium of weak electrolytes in the micellar phase.

- The distribution of ions and molecules of weak electrolytes between micelles of surfactants and the aqueous phase.

- The development of a standard state for ions and molecules of weak electrolytes in the micellar phase.

- The development of experimental techniques and approaches to detecting the 
neutralization of the charged surface of the micelle by ions of weak electrolyte introduced into the system.

\section{References}

[1] Semashko O.V., Burov S.V., Brodskaya E.N. Simulation of the electrical double layer of a spherical micelle of an anionic substance with regard to the solvent structure. Colloid. J. 2009;71(6): 829-834.

DOI: $10.1134 / \mathrm{S} 1061933 X 09060143$

[2] Us'yarov O.G. Dvoynoy elektricheskiy sloy mitsell ionnykh pav $\mathrm{V}$ prisutstvii fonovogo elektrolita. 1. Nizkokontsentrirovannyye mitsellyarnyye rastvory dodetsilsul'fata natriya. Kolloidnyi Zhurnal. 2007; 69(1):102-110.

[3] Adamson A.W., Gast A.P. Physical Chemistry of Surfaces. 6th Ed. N.Y.: John Wiley \& Sons, Inc.; 1997, 784 p.

[4] Lebed V.I., Mchedlov-Petrosyan N.O., Kholin Yu.V. Nauchnoe nasledie N.A. Izmailova i aktualni problemu fizicheskoi khimii. Kh.: KhNU imeni V.N. Karazina; 2007, 675 s.

[5] Hartley G.S. The effect of long-chain salts on indicators: the valence-type of indicators and the protein error. Trans. Faraday Soc. 1934; 30: 444-450.
DOI: $10.1039 /$ TF9343000444

[6] Hartley G.S., Roe J.W. Ionic concentrations at interfaces. Trans. Faraday Soc. 1940; 35: 101-109.

DOI: 10.1039 / TF9403500101

[7] Vlasova N.N. Sravneniye modeley kompleksoobrazovaniya na poverkhnosti dlya kolichestvennogo opredeleniya kislotnykh svoystv vysokodispersnogo kremnezema. Sbornik. Khimiya, fizika i tekhnologiya poverkhnosti. 2008; 14: 6-15.

$$
\text { Mchedlov-Petrosyan }
$$

N.O.

Differentsirovaniye sily organicheskikh kislot $\mathrm{V}$ istinnykh i organizovannykh rastvorakh. Khar'kov: KHNU imeni V.N. Karazina; 2004, $326 \mathrm{~s}$.

[9] Bondarev N.V. Termodinamika ravnovesiy. Effekty sredy i neyrosetevoy analiz. Saarbrücken: LAP LAMBERT Academic Publishing; 2012, 371 s.

[10] Izmailov N.A. Elektrokhimiya rastvorov. Kharkov: Khark. Gos. Univ.; 1959, 960 s.

[11] Standard Quantitities in Chemical Thermodynamics. Pure Appl. Chem. 1994; 66(3): 533-552. 